\title{
Tax Competition and Strategic Delegation with Interregional Asymmetries in Capital Endowment and Income Inequality
}

\author{
Takahiro Watanabe \\ Graduate School of Economics, Osaka University, Osaka, Japan \\ Email:sge028wt@student.econ.osaka-u.ac.jp
}

How to cite this paper: Watanabe, T. (2019) Tax Competition and Strategic Delegation with Interregional Asymmetries in Capital Endowment and Income Inequality. Theoretical Economics Letters, 9, 1434-1446.

https://doi.org/10.4236/tel.2019.95092

Received: April 15, 2019

Accepted: June 14, 2019

Published: June 17, 2019

Copyright $\odot 2019$ by author(s) and Scientific Research Publishing Inc. This work is licensed under the Creative Commons Attribution International License (CC BY 4.0).

http://creativecommons.org/licenses/by/4.0/ (c) (i) Open Access

\begin{abstract}
This study examines a two-country tax competition model, in which the capital endowment and income inequality are asymmetric in each country. Hwang and Cheo [1] and Peralta and van Ypersele [2] show that when countries differ in capital endowments, the country with the higher capital endowment sets a lower capital tax rate. However, their studies assume that all inhabitants are homogeneous. We extend the models of the two aforementioned studies and conduct an analysis taking into account the asymmetry in income inequality within countries. The tax rate is set by the policy maker elected by majority voting in each country's election. We find that a higher tax rate may be set in the country with higher capital endowment under certain conditions. Further, if the income inequality is sufficiently large, the median voters in each country unambiguously delegate the right to decide the tax rate to residents who prefer a higher tax rate than their own, regardless of the capital endowments of the two countries.
\end{abstract}

\section{Keywords}

Tax Competition, Strategic Delegation, Asymmetries in Capital Endowment and Income Inequality

\section{Introduction}

Recently, the analysis of tax competition is becoming increasingly important because of globalization. The increasing mobility of capital, firms and people as a result of globalization brings the countries of the world into tax competition that attracts mobile tax base. As a result, the tax rates are reduced excessively and the loss of potential tax revenue is a major problem, especially in developed coun- 
tries. Therefore, in developed countries, efforts are being made to eliminate harmful tax competition.

Additionally, globalization affects the social situation around the world. In particular, the widening of income inequality and the poverty of developed countries is a serious problem. OECD [3] shows that the share of the richest $1 \%$ in all pre-tax income has more than doubled since 1980, reaching almost $20 \%$ in 2012. This trend has also been observed in other developed countries. These international (in developing vs. developed countries) and intra-national (income inequality) asymmetries may influence the policies implemented by the politicians. In developed countries with large tax base, politicians who decide lower tax rates may be elected in order to prevent the outflow of the tax base. On the other hand, in countries with large income inequality, politicians who decide higher tax rates may be elected as many of the population prefer more income redistribution and public services. Baldwin and Krugman [4] show that the average corporate tax rate (total corporate tax revenue divided by GDP) has increased between the 1980s and 2000 in European countries. We may be able to explain the cause of this trend as the widening of income inequality. Therefore, in this study, we conduct an analysis taking into account these two asymmetries, and clarify how each asymmetry affects the tax rate of each country. Recent trends suggest that tax competition research considering these asymmetries has important implications for theoretical and empirical analysis.

\section{Review of the Related Literature}

There are several studies on tax competition taking into account regional asymmetry. Bucovetsky [5], Wilson [6], Hwang and Cheo [1] and Peralta and van Ypersele [2] analyze models of tax competition, considering the asymmetry among countries. The first two studies take into account the asymmetry in population size among the countries and the other two studies the asymmetry in capital endowments among countries. Hwang and Cheo [1] and Peralta and van Ypersele [2] show that, when countries differ in capital endowments, the country with the higher capital endowment sets a lower capital tax rate because they export the capital to the country with the lower capital endowment as a capital exporting country and prefer a lower tax rate to increase their net capital price. However, these models assume that all inhabitants are homogeneous and that the tax rate in each country is set by a benevolent government (social welfare maximizers).

Persson and Tabellini [7] [8] and Ihori and Yang [9] consider the heterogeneity of individuals and analyze the tax competition under representative democracy ${ }^{1}$. Ihori and Yang [9] apply the citizen-candidate model proposed by Osborne and Slivinski [12] and Besley and Coate [13], and show that a decisive voter (i.e. the median voter in majority voting) in the election delegates the authority of setting the tax rate to residents who prefer a higher tax rate compared ${ }^{1}$ Borck [10] and Fuest and Huber [11] analyze the tax competition under direct democracy. 
to himself/herself. This is called strategic delegation. Since intraregional political competition and interregional tax competition work well, they suggest that the optimal provision of public goods may be realized, unlike the standard tax competition model by Wilson [14] and Zodrow and Mieszkowski [15]. However, their analysis is of symmetrical tax competition and political competition.

As asymmetry among countries, Persson and Tabellini [7] and Gottschalk and Peters [16] consider the heterogeneity of skewedness of income (wealth), namely, the position of the median voter in each country. They show that, for a lower share of median income against domestic gross income, a higher tax rate is set because the poor prefer a higher tax rate for income redistribution. Thus, the heterogeneity of the position of the median voter in each country causes the tax and capital allocation gaps. In addition, Ogawa and Susa [17] extend the results of Ihori and Yang [9] and build a model of asymmetric tax competition and political competition by incorporating asymmetries of production technology and of the position of the median voter among countries. In their study, the country with the higher (lower) production technology becomes a capital importing (exporting) country and has an incentive to set a higher (lower) tax rate to decrease (increase) their net capital price. Therefore, when technological asymmetry is significantly large, the median voter chooses a candidate whose capital share is higher than his/her own share, unlike in result of Ihori and Yang [9]. Further, Nishimura and Terai [18] consider the asymmetry of capital endowment among countries, but not the asymmetry of income distribution ${ }^{2}$. Their results, as well as those of Hwang and Cheo [1] and Peralta and van Ypersele [2], show that a lower tax rate is set in the country with higher capital endowment.

However, what happens when there is asymmetry of income inequality among countries? When the income inequality in a country is large, many of the country's residents, because of their preference for income redistribution, may try to elect as policy makers those who decide higher tax rates. When there is asymmetry of income inequality, this effect differs between countries, so the result indicated by Hwang and Cheo [1], Peralta and van Ypersele [2], and Nishimura and Terai [18] that a low tax rate is set in the country with high capital endowment may change. Therefore, we consider not only the asymmetry of capital endowment but also of income inequality among countries as in Persson and Tabellini [7], Gottschalk and Peters [16], and Ogawa and Susa [17]. As a result, under certain conditions, a higher tax rate is set in the country with higher capital endowment.

The remainder of this paper is structured as follows: In Section 2, we explain the model with the two types of asymmetries among countries. In Section 3, we derive the equilibria of our model and show the main results in Section 4. Sec${ }^{2}$ Nishimura and Terai [18], as well as Ogawa and Susa [17], also examine strategic delegation, considering the asymmetry of production technology within each country. Further, they, as well as Bucovetsky [5] and Wilson [6], examine the asymmetry of population size. In addition, their study compares the utility of the median in strategic delegation and self-representation, taking these asymmetries into consideration. 
tion 5 concludes this paper.

\section{The Model}

Consider an economy consisting of two countries (or regions), $i=L, S$. The number of residents in country $i$ is denoted by $N_{i}$. The total amount of capital initially owned by residents in country $i$ is $K_{i}$, and resident $j$ in country $i$ has $\theta_{i j} \bar{k}_{i}$ units of capital, where $\bar{k}_{i} \equiv \bar{K}_{i} / N_{i}$ denotes the average amount of initially endowed capital in country $i$, and $\theta_{i j}$ is defined as $\bar{k}_{i j} / \bar{k}_{i}$, the ratio of the country's average amount of initially endowed capital and the capital amount initially owned by resident $j$ in country $i$. Thus, if resident $j$ in country $i$ has initial capital endowment equal to the average, then $\theta_{i j}=\bar{k}_{i} / \bar{k}_{i}=1$. Furthermore, we denote the position of the median in country $i$ as $\theta_{i M}$. Since right-skewed income distributions are often observed in practice, we assume that $\theta_{i M} \in[0,1), i=L, S^{3}$. In this model, we regard the difference between $\theta_{i M}$ and the mean (i.e. 1) as the income inequality in each country. For example, if the income inequality in country $L$ is larger than that in country $\mathcal{S}$, then $\theta_{L M}<\theta_{S M}$.

We assume that the capital endowment per capita in country $L$ is higher than that in country $S$, i.e. $\bar{k}_{L}>\bar{k}_{S}$, but the population of each country is the same. We express the relationship between the capital endowments of each country as $\bar{k}_{L}=\alpha \bar{k}_{S}$, where $\alpha>1$.

All firms in each country are participants in a perfectly competitive market and produce numeraire private goods with Constant-Return-to-Scale technology, employing labor and capital according to the production function

$F\left(K_{i}, N_{i}\right)=\left(a-\left(K_{i} / N_{i}\right)\right) K_{i}$. Here, we assume that all residents supply their labor force inelastically. Additionally, we can rewrite this production function in terms of per-capita as $f\left(k_{i}\right)=\left(a-k_{i}\right) k_{i}$, where a captures the level of productive efficiency of the firms in country $i$ and $k_{i}$ denotes the amount of capital employed by the firms in country $i$.

The government in country $i$ levies unit tax rate $t_{i}$ on the capital employed by the firms in the country. Perfect mobility of capital between the two countries is assumed here. In addition to the mobility, market clearing conditions imply

$$
\begin{gathered}
f^{\prime}\left(k_{i}\right)-t_{i}=r, i=L, S \\
\bar{k}_{L}+\bar{k}_{S}=k_{L}+k_{s}
\end{gathered}
$$

where $r$ is the capital price. From Equations (1) and (2), we can derive the amount of capital employed in country $i$ and the capital price as

$$
\begin{gathered}
k_{i}=\kappa-\frac{1}{4}\left(t_{i}-t_{-i}\right) \\
r=a-2 \kappa-\frac{1}{2}\left(t_{i}+t_{-i}\right)
\end{gathered}
$$

where $\kappa=\left(\bar{k}_{L}+\bar{k}_{S}\right) / 2$. As mentioned above, the government in each country ${ }^{3}$ In Ogawa and Susa [17], the case where $\theta_{i M} \geq 1$ is also analyzed, but the main result is discussed for $\theta_{i M}<1$. 
levies unit tax on employed capital and redistribute the tax revenue to every resident within the country in a lump-sum manner. Hence, the budget constraint of country is government becomes

$$
g_{i}=t_{i} k_{i}
$$

The income of each resident in country $i$ is composed of the labor income $f\left(k_{i}\right)-\left(r+t_{i}\right) k_{i}$, the return from capital endowed initially and invested to the market $r \bar{k}_{i j}$, and the lump-sum transfer from the government $t_{i} k_{i}$. Let the utility function of resident $j$ in country $i$ be linear as $u_{i j}=c_{i j}$ where $c_{i j}$ is defined to be the level of consumption of private goods. As the price of private goods is defined as 1 and the consumer's budget constraint is given by $f\left(k_{i}\right)-\left(r+t_{i}\right) k_{i}+r \bar{k}_{i j}+t_{i} k_{i}$, the utility function of resident $j$ in country $i$ is as follows:

$$
u_{i j}=c_{i j}=\left(a-k_{i}\right) k_{i}+r\left(\theta_{i j} \bar{k}_{i}-k_{i}\right)
$$

\section{Equilibrium}

We define the timing of the game as follows:

1) Simultaneously in each country, a policy maker is elected from among the residents through majority voting. The authority to set a capital tax rate within a country is delegated to a resident selected in this election.

2) A capital tax rate $t_{i}$ is chosen by the policy maker selected through the election in the Stage 1. After a capital tax rate is set within each country, firms produce private goods to maximize their profits and residents consume these goods according to their budget constraints.

We solve the model backward, following the concept of a subgame perfect Nash equilibrium.

\subsection{Second Stage: Tax Rate Determination by Policy Maker under Tax Competition}

Let the utility level of the policy maker in country $i$ be denoted by $u_{i p}$ and the policy maker have $\theta_{i p} \bar{k}_{i}$ units of capital. Taking the capital tax rate in the other country $t_{-i}$ as given, the policy maker sets the capital tax rate of his/her country to maximize his/her utility.

$$
\begin{gathered}
\max _{t_{i}} u_{i P}=\left(a-k_{i}\right) k_{i}+r\left(\theta_{i P} \overline{k_{i}}-k_{i}\right) \\
\text { s.t. } k_{i}=\kappa-\frac{1}{4}\left(t_{i}-t_{-i}\right) \\
r=a-2 \kappa-\frac{1}{2}\left(t_{i}+t_{-i}\right)
\end{gathered}
$$

The reaction function of country $i$ is derived from the first-order condition of the maximization problem above as

$$
t_{i}\left(t_{-i}\right)=\frac{1}{3} t_{-i}+\frac{4}{3}\left(\kappa-\theta_{i p} \bar{k}_{i}\right)
$$


Solving Equation (7) for $i=L, S$, we obtain:

$$
\begin{gathered}
t_{i}=2 \kappa-\frac{3}{2} \theta_{i P} \bar{k}_{i}-\frac{1}{2} \theta_{-i P} \bar{k}_{-i} \\
k_{i}=\kappa+\frac{1}{4}\left(\theta_{i P} \bar{k}_{i}-\theta_{-i P} \bar{k}_{-i}\right) \\
r=a-4 \kappa+\theta_{i P} \bar{k}_{i}+\theta_{-i P} \bar{k}_{-i}
\end{gathered}
$$

\subsection{First Stage: Selection of Policy Maker}

In the first stage, the policy maker is elected by residents' majority voting in each country. The residents of each country vote for an individual based on the amount of capital he/she owns. Because of the median voter theorem, the resident located at the median of the distribution of capital share is the decisive voter in his/her country. We denote the capital endowment of the median voter in country $i$ as $\theta_{i M} \bar{k}_{i}$. Taking into account the result of the second stage and the choice of other country as given, median voter in each country decides to whom delegate the right to decide the tax rate. Hence, the maximization problem considered by median voter in country $i$ is as follows:

$$
\begin{gathered}
\max _{\theta_{i P}} u_{i M}=\left(a-k_{i}\right) k_{i}+r\left(\theta_{i M} \bar{k}_{i}-k_{i}\right) \\
\text { s.t. } k_{i}=\kappa+\frac{1}{4}\left(\theta_{i P} \bar{k}_{i}-\theta_{-i P} \bar{k}_{-i}\right) \\
r=a-4 \kappa+\theta_{i P} \bar{k}_{i}+\theta_{-i P} \bar{k}_{-i}
\end{gathered}
$$

The reaction function of country $i$ is derived from the first-order condition of the maximization problem above as

$$
\theta_{i P}\left(\theta_{-i P}\right)=\frac{1}{5 \bar{k}_{i}} \theta_{-i P} \bar{k}_{-i}+\frac{4}{5 \bar{k}_{i}}\left(2 \theta_{i M} \bar{k}_{i}-\kappa\right)
$$

Solving Equation (11) for $i=L, S$, we obtain:

$$
\begin{gathered}
\theta_{i P}^{*}=\frac{5}{3} \theta_{i M}+\frac{1}{3} \theta_{-i M} \frac{\bar{k}_{-i}}{\bar{k}_{i}}-\frac{\kappa}{\bar{k}_{i}} \\
t_{i}^{*}=4 \kappa-\frac{8}{3} \theta_{i M} \bar{k}_{i}-\frac{4}{3} \theta_{-i M} \bar{k}_{-i} \\
k_{i}^{*}=\kappa+\frac{1}{3}\left(\theta_{i M} \bar{k}_{i}-\theta_{-i M} \bar{k}_{-i}\right) \\
r^{*}=a-6 \kappa+2\left(\theta_{i M} \bar{k}_{i}+\theta_{-i M} \bar{k}_{-i}\right)
\end{gathered}
$$

\section{Analysis}

First, we compare tax rates and capital amounts of each country in the equilibrium. Here, we define $\alpha \equiv \bar{k}_{L} / \bar{k}_{S}, \beta \equiv \theta_{S M} / \theta_{L M}$. Then, from Equations (13) and (14), in the equilibrium, the following proposition holds for the tax rate and the capital allocation in each country.

Proposition 1. Comparison of the equilibrium tax rate and capital allocation in each country. 
a) $t_{L}^{*}>t_{S}^{*}$ and $k_{L}^{*}<k_{S}^{*}$ if $\alpha<\beta$

b) $t_{L}^{*}=t_{S}^{*}$ and $k_{L}^{*}=k_{S}^{*}$ if $\alpha=\beta$

c) $t_{L}^{*}<t_{S}^{*}$ and $k_{L}^{*}>k_{S}^{*}$ if $\alpha>\beta$

For the proof, see Appendix A. The intuition behind Proposition 1 is as follows: We have $\alpha>1$ because we assume that $\bar{k}_{L}>\bar{k}_{S} . \alpha$ is a parameter that represents the asymmetry in the capital endowment in each country. Capital endowment induces a downward pressure on the tax rate, since countries that own relatively large amounts of capital dislike a low capital price $r . \beta$ is a parameter that represents the asymmetry of income inequality in each country. Income inequality induces an upward pressure on the tax rate, since residents prefer a larger income transfer. When the income inequality in country $L$ is relatively large (small) compared to that in country $\mathcal{S}, \beta>(<) 1$ since $\theta_{S M}>(<) \theta_{L M}$. Therefore, if the income inequality in country $L$ is relatively large, the capital endowment of the median voter in country $L$ may became relatively small compared to that of the median voter in country $S\left(\alpha<\beta \Leftrightarrow \theta_{L M} \bar{k}_{L}<\theta_{S M} \bar{k}_{S}\right)$. Then, the equilibrium tax rate of country $L$ may become relatively high even if country $L$ has a relatively high capital endowment (showed in Proposition 1(a)). This result is different from those of Hwang and Cheo [1], Peralta and van Ypersele [2], and Nishimura and Terai [18].

On the other hand, even if income inequality in country $L$ is large, when the capital endowment (i.e. $\alpha$ ) is sufficiently high, we have $\alpha>\beta$. Then, a lower tax rate is set in country $L$ with a larger income inequality than that in county $S$ (showed in Proposition 1(c)). This is a different result from that in Gottschalk and Peters [16].

Nishimura and Terai [18] analyze the case where $\theta_{L M}=\theta_{S M}$ and $\bar{k}_{L}>\bar{k}_{S}$. Then, Equations (13) and (14) can be rewritten as follows:

$$
\begin{gathered}
t_{i}^{*}=4 \kappa-\frac{4}{3} \theta_{M}\left(2 \bar{k}_{i}+\bar{k}_{-i}\right) \\
k_{i}^{*}=\kappa+\frac{1}{3} \theta_{M}\left(\bar{k}_{i}-\bar{k}_{-i}\right)
\end{gathered}
$$

Since $t_{L}^{*}-t_{S}^{*}=-(4 / 3) \theta_{M}\left(\bar{k}_{L}-\bar{k}_{S}\right)<0$ and $k_{L}^{*}-k_{S}^{*}=(2 / 3) \theta_{M}\left(\bar{k}_{L}-\bar{k}_{S}\right)>0$, we obtain $t_{L}^{*}<t_{S}^{*}$ and $k_{L}^{*}>k_{S}^{*}$. Now, we have $\theta_{L M}=\theta_{S M} \Leftrightarrow \beta=1$, so this case corresponds to Proposition 1(c). Therefore, a lower tax rate is set in country $L$.

Gottschalk and Peters [16] analyze the case where $\bar{k}_{L}=\bar{k}_{S}=\bar{k}$ and $\theta_{L M} \neq \theta_{S M}$. Then, because of $\alpha=\bar{k}_{L} / \bar{k}_{S}=1$, Equations (13) and (14) can be rewritten as follows:

$$
\begin{gathered}
t_{i}^{*}=4 \bar{k}-\frac{4}{3}\left(2 \theta_{i M}+\theta_{-i M}\right) \bar{k} \\
k_{i}^{*}=\bar{k}+\frac{1}{3}\left(\theta_{i M}-\theta_{-i M}\right) \bar{k}
\end{gathered}
$$

Since $t_{L}^{*}-t_{S}^{*}=-(4 / 3)\left(\theta_{L M}-\theta_{S M}\right) \bar{k}$ and $k_{L}^{*}-k_{S}^{*}=(2 / 3)\left(\theta_{L M}-\theta_{S M}\right) \bar{k}$, we have $t_{L}^{*}>(<) t_{S}^{*}$ and $k_{L}^{*}<(>) k_{S}^{*}$ when $\beta>(<) 1 \Leftrightarrow \theta_{S M}>(<) \theta_{L M}$. These results correspond to Proposition 1, parts (a) and (c), respectively. Therefore, a 
higher tax rate is set in the country with the larger income inequality (i.e. smaller $\left.\theta_{i M}\right)$ and the equilibrium capital amount becomes relatively small.

Here, we consider the capital allocation of the two countries optimized by a social planner. We denote the optimal capital allocation of each country as $\left(k_{L}^{f b}, k_{S}^{f b}\right)$. These are determined by the first-order condition of the optimization problem $\sum_{i} f\left(k_{i}\right)$ sub to (2). Therefore, we obtain the following:

$$
k_{L}^{f b}=k_{S}^{f b}=\kappa
$$

Hence, $k_{L}^{*}=k_{S}^{*}=k_{L}^{f b}=k_{S}^{f b}=\kappa$ holds when $\alpha=\beta$. Since $\beta<1$ when $\theta_{S M}<\theta_{L M}$, if the income inequality in country $L$ is smaller than that in country $S$, the optimal capital allocation is not achieved. However, if the income inequality in country $L$ is larger than that in country $S, \alpha=\beta$ may hold because $\beta>1$. Therefore, it can be said that, for the optimal capital allocation, it is desirable for the income inequality in the country with the higher capital endowment to be relatively large.

Moreover, the following proposition holds for the strategic delegation in each country:

Proposition 2. Direction of strategic delegation in each country.

$$
\theta_{i P}^{*} \gtreqless \theta_{i M} \Leftrightarrow \theta_{i M} \bar{k}_{i} \gtreqless k_{i}^{*}
$$

where $k_{i}^{*}=\kappa+\frac{1}{3}\left(\theta_{i M} \bar{k}_{i}-\theta_{-i M} \bar{k}_{-i}\right)$

For the proof, see Appendix B. The intuition behind Proposition 2 is as follows: We can write $u_{i M}^{*}=\left(a-k_{i}^{*}\right) k_{i}^{*}+r\left(\theta_{i M} \bar{k}_{i}-k_{i}^{*}\right)$ as the equilibrium utility of the median voter of country $i$. Regarding the second term in this expression, capital price $r$ has a positive (negative) effect on the median voter's utility if $\theta_{i M} \bar{k}_{i}>(<) k_{i}^{*}$, and, when the tax rate in a country increases (decreases), the capital price in the market decreases (increases) (see Equation (4)). Hence, if the initial capital endowment of the median voter is more than the capital amount in his/her country in equilibrium, that is, $\theta_{i M} \bar{k}_{i}>k_{i}^{*}$, the median voter becomes a capital exporter and he/she strategically delegates the right to decide the tax rate to the rich residents, who prefer a lower tax rate (see Equation(8)). On the other hand, when $\theta_{i M} \bar{k}_{i}<k_{i}^{*}$, the median voter becomes a capital importer and he/she strategically delegates the right to decide the tax rate to poor residents, who prefer a higher tax rate.

More specifically, based on $\alpha, \theta_{L M}$ and $\theta_{S M}$, the direction of strategic delegation in each country is as follows:

Lemma 1.

$$
\begin{array}{ll}
\theta_{L P}^{*} \geq \theta_{L M} \quad \text { if } \theta_{L M}>\frac{3}{4} \text { and } \alpha \geq \frac{3-2 \theta_{S M}}{4 \theta_{L M}-3} \\
\theta_{L P}^{*}<\theta_{L M} \text { if } \theta_{L M}>\frac{3}{4} \text { and } \alpha<\frac{3-2 \theta_{S M}}{4 \theta_{L M}-3} \\
\theta_{L P}^{*}<\theta_{L M} \text { if } \theta_{L M} \leq \frac{3}{4} \\
\theta_{S P}^{*}<\theta_{S M} \text { for all } \alpha, \theta_{L M} \text { and } \theta_{S M}
\end{array}
$$


For the proof, see Appendix $\mathrm{C}$. The intuition behind Lemma 1 is as follows: $\left(3-2 \theta_{S M}\right) /\left(4 \theta_{L M}-3\right)$ is a decreasing function in $\theta_{L M}$ and $\theta_{S M}$ for $\theta_{L M} \in(3 / 4,1)$. When $\alpha$ and $\theta_{L M}$ are large, then the capital endowment of the median voter in country $L\left(\theta_{L M} \bar{k}_{L}\right)$ becomes large and $\alpha>\left(3-2 \theta_{S M}\right) /\left(4 \theta_{L M}-3\right)$ tends to be satisfied. Then, the median voter in country $L$ may become a capital exporter and he/she strategically delegates the right to decide the tax rate to the rich.

On the other hand, the decrease in $\theta_{S M}$, that is, the widening of income inequality in country $S$, increases the equilibrium tax rate set in country $S$ and the equilibrium capital amount in country $L$ may increase. Then, the median voter in country $L$ may become a capital importer and he/she strategically delegates the right to decide the tax rate to the poor.

Further, when the income inequality in country $L$ sufficiently large $\left(\theta_{L M} \leq 3 / 4\right)$, the median voter in country $L$ becomes a capital importer and he/she strategically delegates the right to decide the tax rate to the poor, regardless of the values of $\alpha$ and $\theta_{S M}$. Regarding country $S$, the median voter becomes a capital importer and he/she strategically delegates the right to decide the tax rate to the poor, regardless of the values of $\alpha, \theta_{L M}$ and $\theta_{S M}$.

When $\theta_{L M}=\theta_{S M}=\theta_{M}$, the median voter in country $L$ delegates the right to decide the tax rate to the rich (poor) if $\theta_{M}>3 / 4$ and $\alpha \geq(<)\left(3-2 \theta_{M}\right) /\left(4 \theta_{M}-3\right)$. However, if $\theta_{M} \leq 3 / 4$, the median voter in country $L$ delegates the right to decide the tax rate to the poor, regardless of the value of $\alpha$. The median voter in country $S$ delegates the right to decide the tax rate to the poor, regardless of the values of $\alpha$ and $\theta_{M}$. This result corresponds that in Nishimura and Terai [18]. However, when $\theta_{L M} \neq \theta_{S M}$, there exists a range of $\theta_{L M}$ values for which the direction of the strategic delegation in country $L$ is determined regardless of the value of $\theta_{S M}$, namely, $\theta_{L M} \leq 3 / 4$. When

$\bar{k}_{L}=\bar{k}_{S} \Leftrightarrow \alpha=1$, we have $\alpha=1<\left(3-2 \theta_{S M}\right) /\left(4 \theta_{L M}-3\right)$ since $\theta_{L M} \in[0,1), i=L, S$. Therefore, the median voter in each country delegates the right to decide the tax rate to the poor. This result corresponds to that of Gottschalk and Peters [16]. However, when the asymmetry of capital endowment of each country (i.e. $\alpha$ ) is sufficiently large, the median voter in country $L$ may delegate the right to decide the tax rate to the rich.

\section{Conclusions}

In this study, we analyze a two-country tax competition model, in which capital endowment and income inequality are asymmetric. First, if the income inequality in the country with the higher capital endowment (referred to as country $L$ in this paper) is relatively small, a lower tax rate may be set in country $L$. This result corresponds to those of Hwang and Cheo [1], Peralta and van Ypersele [2], and Nishimura and Terai [18]. On the other hand, if the income inequality in country $L$ is sufficiently large, a higher tax rate may be set in country $L$. This result corresponds to that of Gottschalk and Peters [16]. 
Second, if the asymmetry of capital endowment is sufficiently large, the median voter in country $L$ may delegate the right to decide the tax rate to the rich. However, if the income inequality in country $L$ is sufficiently large, the median voter in country $L$ may delegate the right to decide the tax rate to the poor regardless of the asymmetry of capital endowments in each country and the income inequality in country $S$.

These results have different implications from previous studies and provide new perspectives. In the future, it will be necessary to research whether the results obtained in this paper can be observed in the real world. However, there are several limitations in this research, as there are in Ogawa and Susa [17]: 1) all residents are candidates and 2) all tax revenues are redistributed in a lump-sum manner. Therefore, in future research, more persuasive results may be obtained by endogenously analyzing who is the candidate and considering the preference for public goods.

\section{Acknowledgements}

I am especially grateful to Nobuo Akai for giving me guidance and appropriate advice for completing this paper. In addition, I would like to thank Yukihiro Nishimura and Kazuhiro Yamamoto for their helpful comments and suggestions.

\section{Conflicts of Interest}

The author declares no conflicts of interest regarding the publication of this paper.

\section{References}

[1] Hwang, H. and Cheo, B. (1995) Distribution of Factor Endowments and Tax Competition. Regional Science and Urban Economics, 25, 655-673. https://doi.org/10.1016/0166-0462(95)02086-A

[2] Peralta, S. and van Ypersele, T. (2005) Factor Endowments and Welfare Levels in an Asymmetric Tax Competition Game. Journal of Urban Economics, 57, 258-274. https://doi.org/10.1016/j.jue.2004.10.007

[3] OECD (2014) Focus on Top Incomes and Taxation in OECD Countries: Was the Crisis a Game Changer?

[4] Baldwin, R.E. and Krugman, P. (2004) Agglomeration, Integration and Tax Harmonisation. European Economic Review, 48, 1-23. https://doi.org/10.1016/S0014-2921(02)00318-5

[5] Bucovetsky, S. (1991) Asymmetric Tax Competition. Journal of Urban Economics, 30, 167-181. https://doi.org/10.1016/0094-1190(91)90034-5

[6] Wilson, J.D. (1991) Tax Competition with Interregional Differences in Factor Endowments. Regional Science and Urban Economics, 21, 423-451. https://doi.org/10.1016/0166-0462(91)90066-V

[7] Persson, T. and Tabellini, G. (1992) The Politics of 1992: Fiscal Policy and European Integration. The Review of Economic Studies, 59, 689-701.

https://doi.org/10.2307/2297993 
[8] Persson, T. and Tabellini, G. (1994) Representative Democracy and Capital Taxation. Journal of Public Economics, 55, 5370. https://doi.org/10.1016/0047-2727(94)90080-9

[9] Ihori, T. and Yang, C.C. (2009) Interregional Tax Competition and Intraregional Political Competition: The Optimal Provision of Public Goods under Representative Democracy. Journal of Urban Economics, 66, 210-217. https://doi.org/10.1016/j.jue.2009.08.001

[10] Borck, R. (2003) Tax Competition and the Choice of Tax Structure in a Majority Voting Model. Journal of Urban Economics, 54, 173-180. https://doi.org/10.1016/S0094-1190(03)00037-8

[11] Fuest, C. and Huber, B. (2001) Tax Competition and Tax Coordination in a Median Voter Model. Public Choice, 107, 97-113. https://doi.org/10.1023/A:1010308526469

[12] Osborne, M.J. and Slivinski, A. (1996) A Model of Political Competition with Citizen-Candidates. The Quarterly Journal of Economics, 111, 65-96. https://doi.org/10.2307/2946658

[13] Besley, T. and Coate, S. (1997) An Economic Model of Representative Democracy. The Quarterly Journal of Economics, 112, 85-114. https://doi.org/10.1162/003355397555136

[14] Wilson, J.D. (1986) A Theory of Interregional Tax Competition. Journal of urban Economics, 19, 296-315. https://doi.org/10.1016/0094-1190(86)90045-8

[15] Zodrow, G.R. and Mieszkowski, P. (1986) Pigou, Tiebout, Property Taxation, and the Underprovision of Local Public Goods. Journal of Urban Economics, 19, 356-370. https://doi.org/10.1016/0094-1190(86)90048-3

[16] Gottschalk, S. and Peters, W. (2003) Redistributive Taxation in the Era of Globalization. International Tax and Public Finance, 10, 453-468. https://doi.org/10.1023/A:1024687532464

[17] Ogawa, H. and Susa, T. (2017) Strategic Delegation in Asymmetric Tax Competition, Economics and Politics, 29, 237-251. https://doi.org/10.1111/ecpo.12092

[18] Nishimura, Y. and Terai, K. (2016) The Direction of Strategic Delegation and Voter Welfare in Asymmetric Tax Competition Models. Discussion Papers in Economics and Business, Graduate School of Economics and Osaka School of International Public Policy, Osaka University, Osaka, 16-27. 


\section{Appendix}

\section{Appendix A: Proof of Proposition 1}

From Equations (13) and (14), we obtain:

$$
\begin{gathered}
t_{L}^{*}-t_{S}^{*}=-\frac{4}{3}\left(\theta_{L M} \bar{k}_{L}-\theta_{S M} \bar{k}_{S}\right) \gtrless 0 \Leftrightarrow \alpha \lessgtr \beta \\
k_{L}^{*}-k_{S}^{*}=\frac{2}{3}\left(\theta_{L M} \bar{k}_{L}-\theta_{S M} \bar{k}_{S}\right) \gtrless 0 \Leftrightarrow \alpha \gtrless \beta
\end{gathered}
$$

\section{Appendix B: Proof of Proposition 2}

From Equation (12), we obtain:

$$
\begin{aligned}
\theta_{i P}^{*}-\theta_{i M} \gtrless 0 & \Leftrightarrow \frac{2}{3} \theta_{i M}+\frac{1}{3} \theta_{-i M} \frac{\bar{k}_{-i}}{\bar{k}_{i}}-\frac{\kappa}{\bar{k}_{i}} \gtrless 0 \\
& \Leftrightarrow \frac{2}{3} \theta_{i M} \bar{k}_{i}+\frac{1}{3} \theta_{-i M} \bar{k}_{-i}-\kappa \gtrless 0 \\
& \Leftrightarrow \theta_{i M} \bar{k}_{i}-\frac{1}{3} \theta_{i M} \bar{k}_{i}+\frac{1}{3} \theta_{-i M} \bar{k}_{-i}-\kappa \gtrless 0 \\
& \Leftrightarrow \theta_{i M} \bar{k}_{i}-\left[\kappa+\frac{1}{3}\left(\theta_{i M} \bar{k}_{i}-\theta_{-i M} \bar{k}_{-i}\right)\right] \gtrless 0 \\
& \Leftrightarrow \theta_{i M} \bar{k}_{i} \gtrless k_{i}^{*}
\end{aligned}
$$

\section{Appendix C: Proof of Lemma 1}

First, regarding the strategic delegation in country $L$, the following inequality holds from Proposition 2:

$$
\begin{aligned}
\theta_{L P}^{*}-\theta_{L M} \gtrless 0 & \Leftrightarrow \theta_{L M} \bar{k}_{L}-k_{L}^{*} \gtrless 0 \\
& \Leftrightarrow \theta_{L M} \bar{k}_{L}-\left[\kappa+\frac{1}{3}\left(\theta_{L M} \bar{k}_{L}-\theta_{S M} \bar{k}_{S}\right)\right] \gtrless 0 \\
& \Leftrightarrow\left(-\frac{1}{2}+\frac{2}{3} \theta_{L M}\right) \bar{k}_{L}+\left(-\frac{1}{2}+\frac{1}{3} \theta_{S M}\right) \bar{k}_{S} \gtrless 0 \\
& \Leftrightarrow\left(4 \theta_{L M}-3\right) \alpha \gtrless 3-2 \theta_{S M}
\end{aligned}
$$

When $\quad 4 \theta_{L M}-3>0 \Leftrightarrow \theta_{L M}>3 / 4$ and $\theta_{i M} \in[0,1), i=L, S$, we have $\left(3-2 \theta_{S M}\right) /\left(4 \theta_{L M}-3\right)>1$. Then, we obtain the following inequality:

$$
\theta_{L P}^{*} \gtrless \theta_{L M} \Leftrightarrow \alpha \gtrless \frac{3-2 \theta_{S M}}{4 \theta_{L M}-3}
$$

On the other hand, $\left(4 \theta_{L M}-3\right) \alpha>3-2 \theta_{S M}$ is not satisfied because $4 \theta_{L M}-3 \leq 0$ when $\theta_{L M} \leq 3 / 4$. Hence, we obtain

$$
\theta_{L P}^{*}<\theta_{L M}
$$

Next, we consider the strategic delegation in country $S$. From Proposition 2, we obtain the following inequality: 


$$
\begin{aligned}
\theta_{S P}^{*}-\theta_{S M} \gtrless 0 & \Leftrightarrow \theta_{S M} \bar{k}_{S}-k_{S}^{*} \gtrless 0 \\
& \Leftrightarrow \theta_{S M} \bar{k}_{S}-\left[\kappa+\frac{1}{3}\left(\theta_{S M} \bar{k}_{S}-\theta_{L M} \bar{k}_{L}\right)\right] \gtrless 0 \\
& \Leftrightarrow\left(-\frac{1}{2}+\frac{2}{3} \theta_{S M}\right) \bar{k}_{S}+\left(-\frac{1}{2}+\frac{1}{3} \theta_{L M}\right) \bar{k}_{L} \gtrless 0 \\
& \Leftrightarrow \alpha \lessgtr \frac{4 \theta_{S M}-3}{3-2 \theta_{L M}}
\end{aligned}
$$

When $\theta_{i M} \in[0,1), i=L, S$, we have $\alpha>\left(4 \theta_{S M}-3\right)\left(3-2 \theta_{L M}\right)$ because $\left(4 \theta_{S M}-3\right)\left(3-2 \theta_{L M}\right)<1$. Hence, we obtain

$$
\theta_{S P}^{*}<\theta_{S M}
$$

